\title{
Plant Breeding in the U.S. Private Sector
}

\author{
Fred Bliss \\ Seminis Vegetable Seeds and the University of California, Davis, CA 95617
}

Humankind is completely dependent on plants as a food source, either directly through consumption of plant products or indirectly through domestic animals that eat plant materials. Crop domestication gave rise to cultivars or varieties which became recognized as groups of genetically-related individuals and families, and genetic improvements in plant performance still are delivered through cultivars. It is incumbent on breeders worldwide to accelerate genetic improvement of major and minor crops that provide fiber, energy, calories and the macro- and minor elements required by the growing global population. Furthermore, this must be done in a way that supports longterm sustainability of natural resources while contributing to economic viability throughout the market chain and providing products that consumers find useful.

Important contributions to crop improvement come from hobbyists, selectors, propagators of heirloom seeds and growers as well as professional breeders working in the public and private sectors. However, the latter group - private sector breeders - is the primary focus of this discussion about the type and scope of education and training needed for future professionals.

The most recent reliable estimate of plant breeding jobs in the U.S. comes from 1994 (Frey, 1996), showing that of 2,200 scientific years (SYs), 1,499 (68\%) were in the private sector, 529 (24\%) in state agriculture experiment stations (SAESs) and land grant universities, and 177 (8\%) in the U.S. Department of Agriculture (USDA)-Agriculture Research Service (ARS). Among these, the type of breeding work was categorized in that survey as either cultivar development [1191 (79\%)], germplasm enhancement [165(11\%)], or plant breeding research [143 (10\%)].

An updated estimate of the number and types of jobs will be important for determining trends in employment and how they may impact education and training of future breeders (Morris et al., 2005). It would not be surprising to find that during the past decade, changes have occurred in the types of work being done by breeders as well as scientists and technologists providing essential support for breeding. However, it is likely that roughly two-thirds of the jobs described as plant breeding will continue to be in the private sector and the remainder distributed between SAESs and the USDA-ARS.

Among the 1,500 breeding positions in the private sector, 1,116(75\%) involved agronomic crops and 383 (25\%) involved horticultural crops. In 1994, the 329 private companies that responded indicated that the number of breeders in each company ranged from as few as one to as many as 25 and more. About one-half the total number of breeders were employed in 35 companies with 10 or more per company and one-half in the 291 companies with 9 or fewer breeders.
In summary, in 1994 there were about twice as many breeding jobs in the private than the public sector, and three times as many positions were devoted to agronomic compared to horticultural crops, with breeding positions divided nearly equally between large and small companies. Most likely similar distributions occur today and will continue in the near- to midterm. Therefore, education and training of future breeders should be relevant to the employment prevalent in the profession as well as prepare them to meet changes that will most certainly occur throughout their career. This is true whether the career is in the private or public sector; with agronomic or horticultural crops; in the national and international sectors, and with the same or different companies.

There is little reason to believe that the need for new crop cultivars will diminish in the future because the demand for food and other plant-derived products will increase along with population growth and limited arable land. The actual number of new breeders hired for specific types of breeding activities will undoubtedly change as will the number and types of companies hiring them. Consolidation of private-sector companies engaged in cultivar development continues, but at the same time new ventures are being developed to meet demands for different products in emerging sectors. Accurate predictions of the number of new breeders needed to replace the current supply are difficult. However, if in the U.S. we assume an annual turnover of from $2 \%$ to $5 \%$, 15 to 35 replacement positions will be available each year in the public sector and from 30 to 75 positions in the private sector.

The number of students receiving advanced plant breeding degrees in the U.S. during the years 1995 to 2000 (Guner and Wehner, 2003) appears to match reasonably well the number of breeding jobs available, based on the estimated annual turnover rates. They estimated that 770 domestic and foreign plant breeding students were trained at land-grant universities, of which 360 were domestic and 410 were international in origin. Of this group, 411 received the $\mathrm{PhD}$ and 359 an MS degree. These figures do not take into account the diverse types of education they received or different types of activities they assumed when employed.

\section{BREEDING ACTIVITIES IN THE PRIVATE SECTOR}

The type and scope of activities in a typical private-sector breeding program vary widely according to crop, size of company, resources available, and division of activities among different operating units. Optimally, a wellsupported program includes a breeder, assistant breeder or breeding assistant, technical support scientists in areas of pathology (and entomology), cell biology and tissue culture, applied genomics, plant transformation, quality analy- ses, regulatory affairs, and intellectual property issues, program support people for activities such as greenhouse and field management, pollination, data base management, data analyses, etc. Sometimes, a breeding program includes management of breeder seed, and foundation, stock and commercial seed inventories as well as germplasm collection and evaluation. Also, depending on the organization, some functions of advanced product testing, product development, marketing and sales may be part of breeding activities.

The ideal situation is to have specialists with appropriate training and experience in each of the functional areas, but many programs are far from ideal. Usually, the breeder is expected to handle some of the important related activities, e.g., pathology screening, developing and using molecular markers, etc. besides what are thought of typically as breeding, e.g., crossing, selection, testing, introduction, etc. As new advanced technology becomes available, careful consideration must be given to which subjects are essential vs. desirable components of breeder training, and an appropriate balance struck between specialization and more general education.

Masters and $\mathrm{PhD}$ programs usually are the focus for breeder education and training with some attention to BS curriculum and certification programs. However, because of the range of activities that contribute to a successful commercial breeding effort, there is a need for appropriately trained individuals not only at advanced levels but also with 2-year associate and high school degrees. The cost of a fully funded breeding program in the U.S. is likely to be in the range of $\$ 250,000$ to $\$ 500,000$ annually when all costs are considered (see Frey, 1996 for comparable estimates). Clearly, to assure an acceptable return from this substantial investment requires that all members of the team are well-prepared, competent, and effective.

\section{PLANT BREEDING EDUCATION AND TRAINING}

What defines a plant breeder? Design of relevant education and training programs for future breeders should take into account the qualifications and types of activities employers expect of them. Although the 1994 survey categorized plant breeding activities into cultivar development, germplasm enhancement, and plant breeding research, other surveys and actual job advertisements use different labels of qualifications and job functions. It is instructive to note recent advertisements that include position titles and content since they should reflect what companies feel are their current and future needs.

Advertisements by private sector companies that have appeared in recent issues of CSA News and the ASHS Newsletter contain 
position titles such as squash breeder, plant breeding position, plant breeder, three corn breeding positions, three cotton breeding positions, molecular cotton breeder, senior plant pathologist, molecular marker scientist, research technician-cotton, and research associate for sunflower research and product development. All are associated with one or more of the above three categories of plant breeding activities. Some clearly involve cultivar development while others provide critical support functions. It should be noted that all have requirements or strong suggestions that knowledge of plant breeding principles is either essential or preferred.

Each position description defines in part, "what is a plant breeder?" For example, a breeder may be expected to have a $\mathrm{PhD}$, MS, BS or equivalent degree, develop new cultivars, do germplasm enhancement, prebreeding, and population development, conduct field trials, use statistical packages for data analyses, practice marker-assisted selection, conduct pathology screens for disease resistance, carryout fundamental research on new breeding methods, mentor junior breeders, communicate effectively with co-workers in two or more languages, and lead a breeding team. To meet even a subset of these qualifications requires both breadth and depth of education and training. Almost any combination of required qualifications can be found in both large and small companies with regional, national or global business, and in the public as well as private sector. What's more, the first job of only a few people will be the one they envision during their school years. Most are likely to work for several companies, and even when they remain with the same employer, they will either want or be expected to assume different responsibilities and challenges throughout their career.

Programmatic content - past and future. To have an idea of what areas of academic education and training are most relevant to breeders in the private sector, breeders (cultivar developers) employed by Seminis Vegetable Seeds were asked to complete an "Opinion Survey about Education and Training for Plant Breeding." For each of 16 areas of academic education (Table 1), they were asked about the number of weeks of instruction they received, how much they used that area of training during their professional career (occasional, intermittent or daily), whether they received adequate amount and depth of exposure in the area, and importance for future breeder training (little value, helpful but nonessential or essential for success). The responses by 27 horticultural cultivar developers were analyzed.

Those responses should be considered in the context that the Seminis breeders who responded are strongly focused on commercial cultivar development. For the most part, support activities are provided by specialists, e.g., pathology screening by the Pathology Department, molecular marker analyses by the Applied Genomics Group, etc. The responses reflect the reality of these breeders, but for situations where support services are not provided, they may have responded differently.
The responses support the idea that broad education and training are important but that some disciplines deserve more intensive and extensive emphasis depending on the type of activities a breeder is expected to perform.

My opinion, based on breeder responses I received, my experience as major professor for some $35 \mathrm{MS}$ and $\mathrm{PhD}$ students at the University of Wisconsin-Madison and University of California-Davis and from following the careers of these students as well as numerous others who completed the course in Principles of Plant Breeding, is that several areas are very important as the foundations for cultivar developers in the private sector (Table 1). These include principles and practice of plant breeding; general statistics and experimental design; mating systems, populations and comparative gain from selection; and pathology and disease resistance. Emerging as important areas are strategies for and implementation of integrated molecular-assisted breeding; software and data base management; management, business, ethics and intellectual property; and finally practical experience with real plant populations and a practicing plant breeder. The other areas of study represent opportunities for enrichment depending on the time available and desire to specialize within plant breeding and genetics.

Structured education and training in the foundation sciences and technology that support breeding is essential, but it is also important to develop and enhance personal and professional skills (Table 2). These include effective oral and written communication; management of people, time, and resources; innovation and openness to change; interactivity and willingness to collaborate with diverse types of people, proficiency in computer software and data base management; ability to teamwork and network; and fluency in multiple languages. The importance of having one or more mentors in both our personal and professional lives often is overlooked. These are people we can trust and rely on in good times and bad for sound advice and steady guidance, for not only what we want to hear, but for what we should hear. We should learn from good mentors how to provide this advice for the next generation of breeders.

\section{INSTITUTIONS, PROGRAMS, AND CURRICULA}

The survey by Guner and Wehner (2003) found that from 1995 to 2000 , plant breeding students were trained at about 40 land-grant universities. However, one-half of all domestic and international degrees were granted at only six institutions. The important question for the future is will the universities who have had strong programs in the past continue and make programmatic changes required for future breeder training? If not, which ones will take their places?

The fact that an estimated 770 plant breeding students received advanced degrees in this 5-year period suggests that U.S. land-grant universities historically have had the capacity to produce enough well-trained breeders for jobs worldwide. However, there is concern about whether future demands can be met because of declining public funds for higher education in general, lack of funding for plant breeding in the public sector, and replacement of breeding-oriented faculty with people having other interests and focus.

Because of the limited resources likely to be available, it may be desirable for groups of universities, institutes, international centers and private companies to explore collaborative

Table 1. Perceived current use and future value of different areas of academic education and training for private-sector horticultural cultivar developers.

\begin{tabular}{lcc}
\hline Academic area & Current use & Future value \\
\hline Principles and practice of plant breeding & High & High \\
Experimental design and applied statistics & Low & Moderate \\
Mendelian/transmission genetics & Moderate & High \\
Quantitative/biometrical genetics and Selection Theory & Moderate & High \\
Molecular genetics and applied genomics & Low & Moderate \\
Biochemical and physiological genetics & Low & Low \\
Cytology and cytogenetics & Low & Low \\
Evolution and population genetics & Moderate & Moderate \\
Plant reproductive biology & Moderate & Moderate \\
Whole-plant biochemistry and crop physiology & Low & Moderate \\
Plant pathology and microbial genetics & Moderate & Moderate \\
Entomology & Low & Low \\
Cell and tissue culture methods & Low & Low \\
Genetic transformation, transgene manipulation & Low & Low \\
Business management & Moderate & Moderate \\
Intellectual property rights and protection & Low & Moderate \\
\hline
\end{tabular}

Table 2. Personal skills needed for success in the private-sector breeding.

Necessary skill

Effective oral and written communication

Efficient management of people, time and resources

Innovative and open-minded to change

Interactive and collaborative with diverse people

Willing and able to teamwork and network

Analytical, critical and constructive thinking for effective problem-solving

Proficiency in computer software application and database management

Bilingual or multilingual 
education and training programs. I believe it is important to support at least several such centers to provide diversity of ideas and approaches.

Preparation for careers in commercial plant breeding should include competence not only in the scientific areas but also business management and intrepreneurship, ethics, intellectual property creation and management and regulatory affairs. Especially breeders in the private sector are finding that expertise in these areas is very desirable and required for success in some cases.

There is an opportunity for programs and curricula in addition to the usual BS, MS, and $\mathrm{PhD}$ programs. For example, a combined academic and business degree will be attractive. The idea of collaborative breeding whereby farmers and growers work in concert with professional breeders may require focused curriculum or new courses. The possibility of training to be a parabreeder (similar to a paralegal) might offer opportunities for needed expertise in countries where extensive support for traditional academic degrees is not likely. Unquestionably, there is a need for continuing education for private sector breeders to assure that they have the opportunity to remain knowledgeable of new scientific information they can use in their everyday work.

\section{SUPPORT FOR BREEDER EDUCATION AND TRAINING}

Viewed in total, the private sector is expected to provide good employment opportunities in plant breeding for cultivar developers and scientists and technologists who are essential to various facets of breeding programs. This includes competent individuals at all education levels from secondary through certificate, degree and advanced degree programs. Current estimates indicate an average annual base salary for plant breeders of about $\$ 80,000$, with a range from $\$ 39,000$ to $\$ 48,000$ to $\$ 115,000$ to $\$ 135,000$. One challenge is to raise awareness of academic counselors about opportunities in plant breeding and to provide them with good information they can give to students. This information would include the activities that go on in plant breeding in the private sector, and finally what are the salary levels and opportunities for professional growth and advancement. It is the responsibility of both the public and private sectors to provide this information to the counselors and students who will become the next generation of plant breeders.

Students and their families increasingly view education as an investment for the future. In addition to choosing a subject of interest, they will raise questions about what is the cost of education for each level, i.e., BS, MS, PhD degrees. Are there opportunities for financial assistance in the form of scholarships, assistantships, loans, part-time employment, etc.? After finishing with a particular degree, what opportunities exist for initial employment in various regions, nationally, internationally, etc.? What are the types of jobs, salaries, advancement, etc. In summary, how good an investment is a degree that will prepare me for a career in plant breeding and/or the support science and technology?

As with other professional programs, support for breeder education and training will come from multiple sources, those sources will be determined in part by who benefits from plant breeding education? There are at least four beneficiaries:

- The student receiving the education.

- Faculty members in the departments providing training through fulfilling their mission of teaching and research.

- Employers in the private and public sectors who rely on the programs to produce the personnel needed for their organizations.

- Society, i.e., taxpayers who depend on plant breeders and others in agriculture for food security.

Shared support for future education and training of breeders means that private com- panies must participate in appropriate ways.

This can include the following:

- Support to current employees for degree/ continuing education including salary, tuition, etc.

- Unrestricted training grants to universities.

- Designated endowments for graduate, undergraduate and professional education in plant breeding.

- On-site support for internships that includes salary, living expenses, travel, etc.

- Participation in teaching and training such as serving on curriculum and degree advisory committees, spending a week as breederin-residence, face-to-face interaction with students via distance learning, and providing instruction in short courses and continuing education.

The future for plant breeding is very exciting because of the continuing need for new crop plant cultivars to sustain our global population and the powerful science and technology that can be used for genetic improvement. But concurrently, there is reason for concern - the dearth of information about this wonderful profession that reaches the best students and the lack of programmatic support for education and training. The convening of this symposium is the first important step toward addressing these concerns and then motivating people and institutions to meet the challenges. The organizers are to be commended.

\section{Literature Cited}

Frey, K.J. 1996. National plant breeding study. I. Human and financial resources devoted to plant breeding research and development in the United States in 1994. Iowa Agr. Home Econ. Expt. Sta. Spec. Rpt. 98.

Guner, N. and T.C. Wehner. 2003. Survey of U.S. land-grant universities for training of plant breeding students. Crop Sci. 43:1938-1944.

Morris, M., G. Edmeades, and E. Pehu. 2006. Building capacity for international plant breeding: What roles for the public and private sector? HortScience 41(1):30-39. 